\title{
Headaches Prevalence in Childhood and Adolescence at Pediatric Neurology Service in Salvador - Brazil
}

\author{
Morais $\mathrm{LB}^{*}$, Tavares $\mathrm{NS}^{2}$ and Primo JRL ${ }^{3}$ \\ ${ }^{1}$ Medical student at the Universidade Salvador - Laureate International Universities, Salvador -Bahia - Brazil Schol- \\ arship CNPq Institucional UNIFACS \\ ${ }^{2}$ Medical student at the Universidade Salvador - Laureate International Universities. Salvador -Bahia - Brazil \\ ${ }^{3}$ Doctor in Medicine, Medical Professor at Universidade Salvador - Laureate International Universities and Medical \\ Coordinator of the Residency Program in Pediatric Neurology at Obras Sociais Irmã Dulce. Salvador- Bahia-Brazil
}

${ }^{*}$ Corresponding author: Morais LB, Medical student at the Universidade Salvador - Laureate International Universities, Salvador -Bahia - Brazil Scholarship CNPq Institucional UNIFACS, E-mail: larissablanc@ gmail.com

Citation: Morais LB, Tavares NS, Primo JRL (2017) Headaches Prevalence in Childhood and Adolescence at Pediatric Neurology Service in Salvador - Brazil. J Neurol Neurol Disord 3(1): 103. doi: 10.15744/24544981.3.103

Received Date: November 25, 2016 Accepted Date: January 24, 2017 Published Date: January 27, 2017

\begin{abstract}
Headache is among the main pediatric symptom and the physicians should meet the diagnostic criteria of the International Headache Society. In a cross-sectional study, during August 2015 to August 2016, the types of headaches and the sociodemographic profile of patients between 4 and 18 years of age were evaluated. The headache patients were previously diagnosed and followed at the Pediatric Neurology Service of Salvador, according to established criteria. The study was approved by Research Ethics Committee and it was carried out with the application of a specific questionnaire. In the overall study population $(\mathrm{N}=58)$ were detected: primary headache migraine type that incapacitated the daily activities in 34/58 (58.6\%) and the socioeconomic profile showed the family income below two salaries (in Real currency) in 38/58 (65.5\%) of the population. As observed in adults, the headaches constitute a disabling diagnosis and it is impactful in the development of activities of daily living in the age group of this study, corroborating the literature on the importance of early diagnosis and therapy.
\end{abstract}

Keywords: Headache; Neurology; Pediatric

\section{Introduction}

The headaches are a very common complaint encountered by health professionals in most of clinical medicine and surgical specialties. This complaint is estimated at $2-4 \%$ of all medical emergency room visits [1]. According to the World Health Organization - WHO, this symptom is among the leading causes of loss of quality of life and its impact can be devastating [2]. Also during the childhood, the headaches are one of the main complaints of the pediatric clinic and there are singularities in its different forms of presentation. The headaches can be considered a warning sign as a symptom due to a serious disease or it may be harmless. Therefore, it must be investigated and not neglected [3]. Since 2004, the International Headache Society (International Headache Society - IHS) has classified headaches assisting clinical practice in diagnosis establishment, prognosis and therapeutic on the diversity of manifestations of all headaches and trigeminal neuralgia [4].

The version III beta International Classification Headache Disorders-3 (ICHD-3) was reviewed in 2015. The nomenclature of many types of headaches in different study centers was uniform and classified them in primary and secondary headaches [5]. In the pediatric population, the types of headaches that are the most popular are migraine and headaches of tension-type [6]. In addition, there are several other primary headaches disorders that are not associated with brain structural damage, but there are migraines associated with sexual activity and cough. Furthermore, migraines usually begin at childhood, adolescence or early adulthood, and occur more often in women than in man, at a ratio of 3:1 [7].

The proper characterization of migraine attacks requires the presence of at least two of the characteristics of pain, which should be accompanied by at least one of the symptoms (nausea, vomiting, photophobia, phonophobia), according to criteria of IHS. A migraine without aura according to the IHS criteria is described as recurring with episodes that last from 4 to 72 hours each, are typically of unilateral location, pulsating, moderate or severe intensity, worsened or aggravated by physical activity routine and 
associated with nausea and photophobia or phonophobia. A migraine with aura is less frequent, which is expressed by visual and / or sensory reversible neurological symptoms that usually develop gradually and precede the headaches with migraine characteristics. Other symptoms in primary headaches such as chronic migraine and probable migraine were described by the ICHD-3 beta review, which headaches aren't better accounted for by other primary headaches diagnostics [5].

Patients with primary headache may present alterations in pain patterns and other clinical manifestations (fever, signs and symptoms of intracranial hypertension) that are characterized as red flags. In these cases physicians should be alert to the possibility of secondary headaches.

Secondary headaches are those attributed to the causative disorders. They may be caused by diseases, demonstrable by clinical or complementary tests. These are examples of secondary headaches: primary facial pain, central facial pain, head and neck pain are mediated by afferent fibers in the trigeminal nerve, nervus intermedius, glossopharyngeal and vagus nerves, and the upper cervical roots via the occipital nerves, and they are called painful cranial neuropathies. The cause may be clear, such as herpes zoster infection or a structural abnormality demonstrated by imaging, but in some cases the cause for neuralgic pain is not found [8].

The diagnosis of headaches is fundamentally clinical and individualized. In view of clinical signs of Red Flags, the complementary tests are indicated for confirmation of possible secondary causes [9]. It is essential that therapy is immediately initiated at the presentation of the prodromal signs or aura, for the efficacy of the drugs used. In children, there are restrictions on the use of some medications that are used in adults. These restrictions are due to the lack of studies on toxic properties, pharmacokinetics and pharmacodynamics in the child population [10]. Non-hormonal anti-inflammatory drugs (ibuprofen) and analgesics (dipirone) are safely and efficaciously used in children's acute attacks [11]. The associated symptoms of headaches corresponding to the gastrointestinal tract (nausea and vomiting), worsening of the general condition and it should be promptly treated. Therefore, the rational therapy for headaches indicates that the abusive use of analgesics correlates with the chronic state of episodic headaches, at all ages [12]. In this way, this study aimed to investigate the prevalent headaches in children and adolescents assisted in the neuropediatric outpatient clinic of the Obras Sociais Irmã Dulce in Salvador/Brazil, to characterize the types of headaches, associated conditions (gender, sociodemographic), besides the evolutionary profile and progression of this condition in this population.

\section{Materials and Methods}

Population and Study Design: Between August 2015 and August 2016, children and adolescents were submitted to an observational, cross-sectional study of prevalence for headaches types in infants and teenagers, with criteria of age groups from 4 to 18 years old to be permitted to have medical admission. The population was constituted by the 58 patients admitted at the neuropediatrics academic outpatient clinic of the Hospital Santo Antônio das Obras Sociais Irmã Dulce in Salvador - Bahia/Brazil. This study was approved by the Ethics Research Committee of Universidade Salvador - Laureate, and The Informed Consent Term was signed by the child's legal guardian. All patients were evaluated by neuropediatricians from the outpatient clinic. These patients answered the adapted questionnaire "Quality of life headache-youth questionnaire". Then, they characterized the demographic and socioeconomic aspects, based in (IBGE) Brazilian Institute of Geography and Statistic (schooling, family income, housing, gender, age in years, ethnicity, origins); comorbidities such as behavior disorders and scholastic learning difficulties, body mass index (BMI), epileptic seizures, eating disorders were also evaluated. The diagnostic criteria for headaches was addressed as location of cephalgia; number, frequency, duration of each headache attack; mode of onset and progression of pain; associated symptoms such as aura and prodromal signs; improvement factors and worsening of pain; and presence of Red Flags. The headaches types diagnoses were according to international classification criteria for headaches (ICHD-3 beta). The diagnosis of secondary headaches were based on clinical history, physical examination, results of laboratory tests and imaging methods (computed tomography and magnetic resonance), available in patient's records. The analysis of the results of this study of frequency also used the measures of central tendency; measures of variability or dispersion that include standard deviation, variance, maximum value, and minimum value that were calculated by the SPSS software.

\section{Results}

Results show that 58 patients had the main complaint of headache upon admission, in the referred outpatient clinic of Neuropediatrics. The mean age of the population was $10.29 \pm 3.84$ years old (ranging from minimum 4 and maximum 18 years old). The male gender exceeded the female gender, $42 / 58(72.4 \%)$ and 16/58 (27.6\%), respectively. All of patients were born in Bahia, about 44/58 (76\%) born in the capital and 14/58 (24\%) other cities of Bahia. So, these data represent the profile of patients.

The socioeconomic aspect showed a family income below two minimum salaries (in Real currency) about 38/58 (65.5\%) for the years $2015 / 2016$ and the diagnosis of poor nutrition in $37 / 58$ (63.8\%). In the others comorbidities that were found $17 / 58$ (29\%) patients with behavioral problems and difficulty learning school; and about 19/58 (33\%) patients suffered epileptic seizures.

The patients or theirs legal guardians declared the skin color as: browns 27/58 (46.6\%), blacks in 15/58 (25.9\%), whites $8 / 58$ (13.8\%), afro-descendants 6/58 (10.3\%) and 2/58 (3.4\%) were not reported (Table 1). The types of headaches observed according to the diagnostic criteria (ICHD-3) had a higher frequency for the primary headaches that corresponded to $24 / 58$ (41.4\%) of the study population while secondary headaches were found 11/58 (19, 1\%). In primary headaches warning signs found (Red Flags) 
at about 23/58 (39.6\%). Thus, these red flags do not constitute demonstrable secondary causes in laboratory and imaging tests (Figure 1). The types of headaches didn't have correlation with ethnicity.

\begin{tabular}{|c|c|c|c|}
\hline \multirow{2}{*}{ Origins } & \multicolumn{2}{|c|}{ Types of Headaches } & \multirow{2}{*}{ Total for origins } \\
\cline { 2 - 3 } & Primary Headaches & Secondary Headaches & \\
\hline $\begin{array}{c}\text { Salvador (Capital of the } \\
\text { State Bahia) }\end{array}$ & $35 / 58(60.5 \%)$ & $9 / 58(15.5 \%)$ & $44 / 58(76 \%)$ \\
\hline Others cities in Bahia & $12 / 58(20.6 \%)$ & $2 / 58(3.4 \%)$ & $14 / 58(24 \%)$ \\
\hline Other state of Brazil & - & - & - \\
\hline Total for types of headaches & $47 / 58(81.1 \%)$ & $11 / 58(18.9 \%)$ & $58(100 \%)$ \\
\hline
\end{tabular}

Table 1: The distribution by types of headache

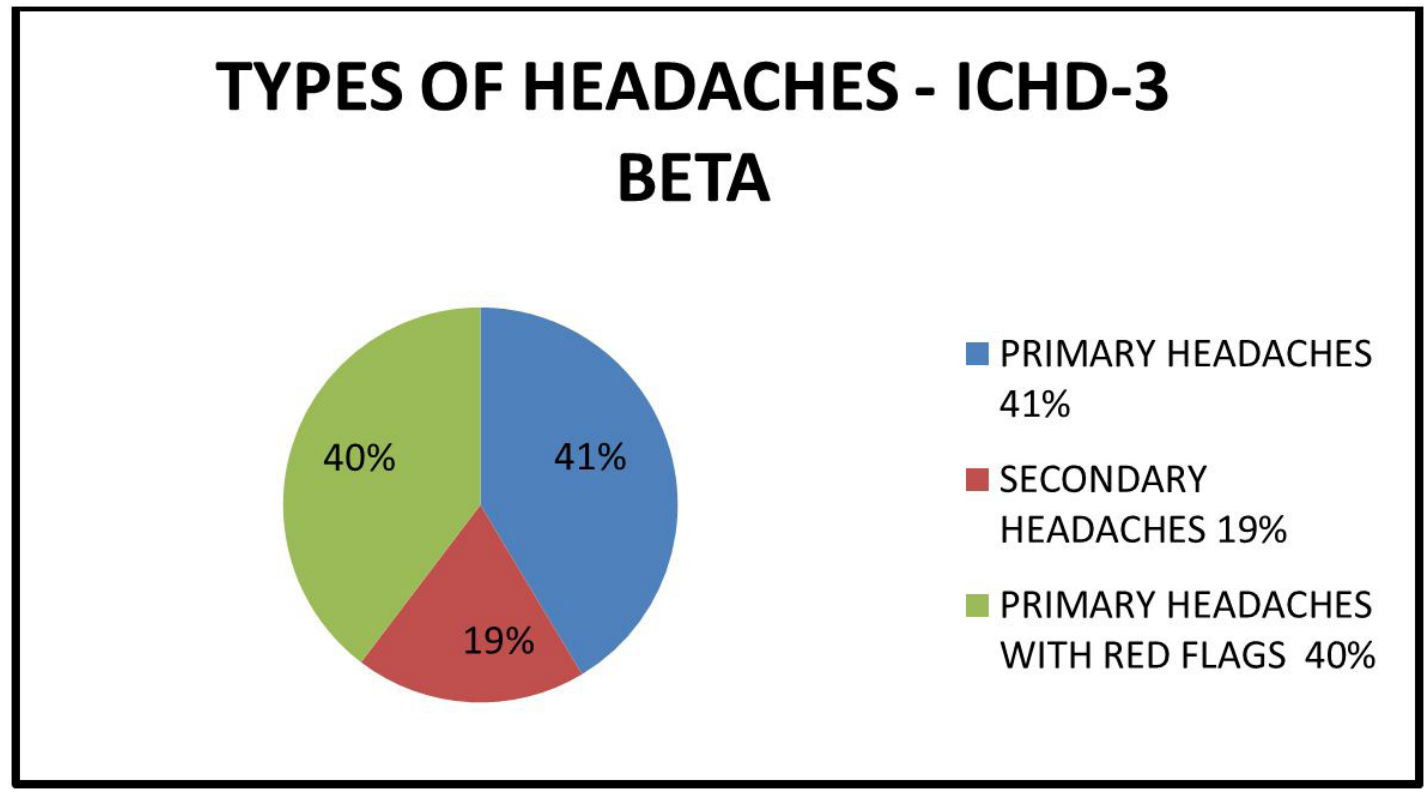

Figure 1: Diagnostic classification of types headaches (Neuropediatrics - OSID 2016)

The number of headaches attacks showed an average frequency of $5.74 \pm 5.25$, ranging from 1 to 30 attacks per month. Moreover, the duration of headaches episodes, in $50 \%$ of cases, the pain was less than or equal to 24 hours. Thus, it was observed that the duration ranged from 30 minutes to 4 hours in $39.6 \%$, and up to seven days in $1.7 \%$ of the patients. It's showed in the headaches characterization in the Table 2.

The classification of the characteristic of the pain for the child and adolescent population had the quality of "tightening" or "pressing" in most cases of type-tension headaches in 32/58 (55.2\%). The "pulsating pain", a criterion seen in migraine, was presented in 23/58 (39. 7\%) of the cases. The "stabbing pain" occurred in 2/58 (3.4\%) and only 1/58 (1.7\%) of the cases did not know how to make this characterization. A severe pain was reported in 34/58 (58.6\%), disabling the activities of daily living.

The migraine topography on the head, in children and adolescents, is more often bilateral, and it was found in $29 / 58$ (50\%). However, the bilateral region is found both in tension-type and in migraine. Unilateral region is usually frontotemporal in migraine headaches, $18 / 58(31.1 \%)$. Alternately unilateral and bilateral in 4/58 (6.9\%), characterizing probable migraine headaches. A nummular headache was localized in a parietal region with sensitivity on the scalp in $3 / 58$ (5.1\%). In $1 / 58$ (1.7\%) the pain's location was non-specific for known causes. Secondary headaches presented a holocranial location in 4/58 (6.9\%) and were caused by trauma or injury to the head and/or neck. This holocranial location could be presented as a chrsonic character of primary headaches, without cranioencephalic alterations in the imaging tests.

Noise, luminosity and odors are triggering factors found in migraine headaches, having a pulsatile character and localizing unilaterally in adults, adolescents and children. But, in children and adolescents it could be exceptionally find in the bilateral frontal region. When we analyzed how these triggering factors started the headaches, we could observe that the patients had more than one triggering factor, among them, luminosity in 34/58 (58.6\%); noise 34/58 (58.6\%); stress 24/58 (41.4\%); physical activity 20/58 (34.5\%); odors $14 / 58(24.1 \%)$ and trauma $10 / 58(17.2 \%)$. In the female population of the study, menstruation was the triggering factor present in 5/16 (31.25\%) of the adolescents. Stress is an important factor for the diagnostic classification of "tension-type headaches", and it was present in both genders. In females, as a triggering factor of headaches, it was represented by $6 / 16(37.5 \%)$ and male by $18 / 42(42.9 \%)$ in this population. The kind of food was not indicated as a triggering factor by this population, but it was diagnosed as inappropriate and poor nutrition. 


\begin{tabular}{|c|c|c|}
\hline Variables & $\mathrm{N}=58$ & $(\%)$ \\
\hline \multicolumn{3}{|l|}{ Gender } \\
\hline Male & 42 & $(72.4) \mathrm{s}$ \\
\hline Female & 16 & $(27.6)$ \\
\hline \multicolumn{3}{|l|}{ Age } \\
\hline$<4$ years old & 3 & $(5.2)$ \\
\hline 5 a 12 years old & 38 & $(65.5)$ \\
\hline 13 a 18 years old & 17 & $(29.3)$ \\
\hline \multicolumn{3}{|l|}{ Ethnicity } \\
\hline Brown & 27 & $(46.6)$ \\
\hline Black & 15 & (25.9) \\
\hline White & 8 & $(13.8)$ \\
\hline Afro-descendants & 6 & $(10.3)$ \\
\hline Not informed & 2 & $(3.4)$ \\
\hline \multicolumn{3}{|l|}{ Family income } \\
\hline$<1$ Salary & 11 & $(19.0)$ \\
\hline 1- 2 Salaries & 27 & $(46.5)$ \\
\hline$>3$ Salaries & 12 & $(20.7)$ \\
\hline Not informed & 8 & $(13.8)$ \\
\hline \multicolumn{3}{|c|}{ Clinical Characteristic of Headaches } \\
\hline \multicolumn{3}{|c|}{\begin{tabular}{c|l}
$\begin{array}{c}\text { Number of attacks per } \\
\text { month }\end{array}$ & \\
\end{tabular}} \\
\hline 1 a 3 attacks/month & 27 & $(46.5)$ \\
\hline 4 a 7 attacks/month & 18 & $(31.1)$ \\
\hline$>8$ attacks/month & 13 & $(22.4)$ \\
\hline \multicolumn{3}{|l|}{ Duration each attack } \\
\hline 30 min to 4 hours & 23 & $(39.6)$ \\
\hline Less than 30 minutes & 17 & $(29.4)$ \\
\hline From 4 to 24 hours & 11 & $(19.0)$ \\
\hline From 24 to 72 hours & 4 & $(6.9)$ \\
\hline From 3 to 7 days & 2 & $(3.4)$ \\
\hline More than 7 days & 1 & $(1.7)$ \\
\hline \multicolumn{3}{|l|}{ Charater of the pain } \\
\hline Pressing & 32 & $(55.2)$ \\
\hline Pulsating & 23 & $(39.7)$ \\
\hline Stabbing & 2 & $(3.4)$ \\
\hline Not informed & 1 & $(1.7)$ \\
\hline \multicolumn{3}{|l|}{ Intensity } \\
\hline Severe & 34 & $(58.6)$ \\
\hline Moderate & 20 & $(34.5)$ \\
\hline Mild & 4 & $(6.9)$ \\
\hline \multicolumn{3}{|l|}{ Location } \\
\hline Unilateral & 18 & $(31.1)$ \\
\hline Bilateral & 29 & $(50.0)$ \\
\hline Holocranial & 4 & $(6.9)$ \\
\hline Alternately Bi/Unilateral & 4 & $(6.9)$ \\
\hline Parietal & 3 & $(5.1)$ \\
\hline \multicolumn{3}{|l|}{ Triggering Factors ${ }^{\star}$} \\
\hline Luminosity & 34 & $(58.6)$ \\
\hline Noise & 34 & $(58.6)$ \\
\hline Odors & 14 & $(24.1)$ \\
\hline
\end{tabular}




\begin{tabular}{|c|c|c|}
\hline Variables & $\mathrm{N}=\mathbf{5 8}$ & $(\%)$ \\
\hline Stress & 24 & (41.4) \\
\hline Physical activity & 20 & (34.5) \\
\hline Trauma & 10 & $(17.2)$ \\
\hline \multicolumn{3}{|l|}{ Associated symptoms ${ }^{*}$} \\
\hline Photophobia & 25 & $(43.1)$ \\
\hline Phonophobia & 21 & $(36.2)$ \\
\hline Nauseas e vomiting & 19 & $(32.8)$ \\
\hline Inappetence & 16 & (27.6) \\
\hline \multicolumn{3}{|l|}{ Worsing Factors } \\
\hline Physical activity & 16 & (27.6) \\
\hline Stress & 13 & (22.4) \\
\hline Odors & 3 & $(5.2)$ \\
\hline Menstruation & 2 & $(3.4)$ \\
\hline Don't worsen & 24 & (41.4) \\
\hline \multicolumn{3}{|l|}{ Pain relieve } \\
\hline Analgesic & 14 & $(24.1)$ \\
\hline Sleep & 13 & (22.4) \\
\hline Analgesic and sleep & 27 & $(46.6)$ \\
\hline Don't improve & 3 & $(5.2)$ \\
\hline Not informed & 1 & (1.7) \\
\hline
\end{tabular}

Table 2: General and clinical aspects that contributed to the diagnostic classification of Types of Headaches (OSID 2016 Neuropediatrics Outpatient Clinic)

Factors associated headaches with family history in first and second degree relatives consanguinity were observed in $20 / 58$ (34.5\%) of the cases. The associated symptoms were present during the headaches: photophobia in 25/58 (43.1\%); phonophobia in $21 / 58$ (36.2\%); nausea and vomiting in 19/58 (32.8\%); and inappetence in 16/58 (27.6\%) in cases with migraine or tension-type primary headaches. Others symptoms were observed such as: conjunctival hyperemia, tearing, nasal congestion, ptosis palpebral, miosis, rhinorrhea and sweat on the forehead. Among these symptoms like conjunctival hyperemia, ocular tearing, nasal congestion and rhinorrhea were more observed in the context of secondary headaches related to infectious or rhinosinusitis.

Failure to recognize headaches worsening factors wasn't detected in 24/58 (41.4\%) of the patients. In the other patients, the physical effort obtained a higher frequency $16 / 58(27.6 \%)$ in cases of migraine, without interfering in cases of tension-type headaches. Stress was observed as worsening headaches in 13/58 (22.4\%), odors 3/58 (5.2\%) and menstruation in adolescents 2/58 (3.4\%).

The factors that relieve headaches were present: the effective treatment prescribed by the neuropediatrician in $14 / 58(24.1 \%)$; Sleep relieved pain in 13/58 (22.4\%); in 27/58 (46.6\%) the drug has a better effect if associated with rest concomitantly. Only one patient was unable to report the improvement factor for headaches. The clinical characteristics that contributed to the diagnostic classification are summarized in the Table 2.

It is important to report that the variables for triggering factors and associated symptoms are independently calculated, with or without each characteristic. Thus, their percentages do not add up to a total of 58 patients as in the other variables. We performed this method of calculation because many patients had more than one characteristic related to these variables. The Table 2 shows the general and clinical aspects that contributed to the diagnostic classification of the types of headaches in the study population.

\section{Discussion}

In the present study, all cases had, as the main complaint of the consultation, the headache symptom, being a high frequency of headaches in the male gender. In the childhood, headaches are a symptom of high prevalence, of broad etiology, with specific diagnostic difficulty, such as the characterization of pain by the child, once this characterization is an important criterion for the classification of headaches [14].

In a survey conducted in the 1950s in Sweden, the prevalence of headaches was found in $40 \%$ of children up to the age of 7 years old, among nine thousand school children evaluated. The type of headache most encountered in this study was migraine followed by episodic tension-type [15].

These findings differ from the study carried out with students between 10 and 18 years old, in Porto Alegre (Brazil), which a high prevalence of tension headache was found (72.8\% of the casuistry studied), followed by migraine in $9.9 \%$ of cases [16]. The secondary headaches occurred less frequently and it was related to head trauma and systemic infections in the body [17]. These are 
evidences that tension-type headaches and migraines are models that perfectly translate primary headaches and these are present in the child and adolescent age group, both in the national and in the world context.

The patients who were studied had more than one type of triggering factor occurring in the same patient. Despite having found odors as a triggering factor and worsening factor, it is not contemplated by ICHD-3. It deserves a detailed study. The most frequent associated symptoms were presented during the headaches as photophobia, phonophobia, nausea and vomiting and inappetence. These factors had also more than one type of associated symptoms occurring in the same patient and in the same time. A severe pain was reported, disabling the activities of daily living. Differently from the adult, it is difficult to obtain from the youngest child data that characterizes how his pain occurs and the associated factors in the characterization of migraine with aura.

However the pain was described more frequently as tightness characterizing the tension type, followed by pulsatile characterizing migraine types. After summing the criteria for headaches, the prevalence found was of the migraine that doesn't characterize the tightness pain. We accredited this fact to the difficulty of the child to express the pain caused by the headaches.

Several aspects of quality of life were compromised in the children and adolescents of the study group, in agreement with those described in the D'Amico (2013) and Arruda et al. (2015) studies, which pointed out the impairments in school performance and cognitive functions in this population $[18,19]$. Therefore, the correct use of the analgesic can improve the quality of life of the patient.

\section{Conclusion}

The headaches were present in the children and adolescent population as seen both in the national and world context. The frequency of primary headaches was higher than the type of secondary headaches, as seen in the primary headaches prototype in this study. In the population of this study, there was a difference between genders, predominating the male gender. Cranial trauma and extra cranial infections were the main causes of secondary headaches types.

\section{Acknowledgments}

We are thankful to the patients for the collaboration of the data collected and to the professionals at the Hospital Santo Antonio of the Obras Sociais Irmã Dulce, for contributing substantially to this study.

\section{References}

1. Arruda MA, Guidetti V (2007) Child’s medical history with headaches: Headache in childhood and adolescence (1th edn). Institute Glia Publisher, Ribeirão Preto, Brazil.

2. World Health Organization - WHO (2016) Headaches disorders, atualizado em abril de 2016.

3. Lima AS, Araújo RC, Gomes MR et al. (2014) Prevalence of headache and its interference in activities of daily living in female adolescents. Revista Paulista de Pediatria, 32(2):256-61.

4. International Headache Society HIS (2004) Headache Classification Committee of Headache Disorders (2th Edn). Cephalalgia, England, 33 (9): 1-160.

5. Belvís R, Mas N, Roig C (2015) Novedades en la reciente Clasificación Internacional de las Cefaleas: clasificación ICHD-III beta. Rev Neurol 60: 81-9.

6. Arruda MA, Arruda R, Guidetti V, Bigal ME (2015) Psychosocial Adjustment of Children With Migraine and Tension-Type Headache - A Nationwide Study. Wiley Periodical Inc, Headache. Ribeirão Preto. 55: 39-50.

7. Sanvito WL, Monzillo PH (1997). Primary headache: clinical and therapeutic aspects. Simpósio cefaleia. Ribeirão Preto. 30(3): 437-448.

8. Coelho MEVX, Costa J, Gomes AJSF, Santana BS, Lima J (2005) Epidemiologic aspects of headache in childhood and adolescence. Migrâneas cefaleias 8: 36-8.

9. Arruda M, Cescut A et al. (2013) Headache and comorbidity in children and adolescents. J Headache Pain 14: 79.

10. Chronicle E, Mulleners W (2008) Fármacos anticonvulsivantes para la profilaxis de la migraña.(2th edn). Chichester, UK.

11. Bigal ME, Bordini CA, Speciali JG (1999) Headache treatment in an emergency unit of the city of Ribeirão Preto, Brazil. Arq Neuro-Psiquiatr 57: 813-9.

12. Siqueira LF (2011). Headache in childhood and adolescence. Pediatria Moderna. 47(1): 5-12.

13. IBGE - Pesquisa Nacional por Amostra de Domicílios Contínua (2015).

14. Puccini RF, Bresolin AMB (2003) Recurrent pains in children and adolescents. J Pediatr 79): S65-S76.

15. Bille B (1997). A 40-year follow up of school children with migraine. Cephalagia, 14: 488-91.

16. Barea LM, Tannhauser M, Rotta NT (1996) An epidemiologic Study of headache among children and adolescents of southern Brazil. Cephalaigia 16: 545-9.

17. Haas DC (1996) Cronich post-Traumatic headaches: Classified and compared with natural headeaches. Cephalagia 16: 486-93.

18. D’amico D, Grazzi L, Usai S, Leonardi M, Raggi A (2013) Disability and quality of life in headache: where we are now and where we are heading. Neuro Sci 34: 1378 - 9

19. Arruda MA, Arruda R, Guidetti V, Bigal ME (2015) Feature Articl Psychosocial Adjustment of Children With Migraine and Tension-Type Headache - A Nationwide Study. Wiley Periodical Inc, Headache.Ribeirão Preto, 55: 39-50. 


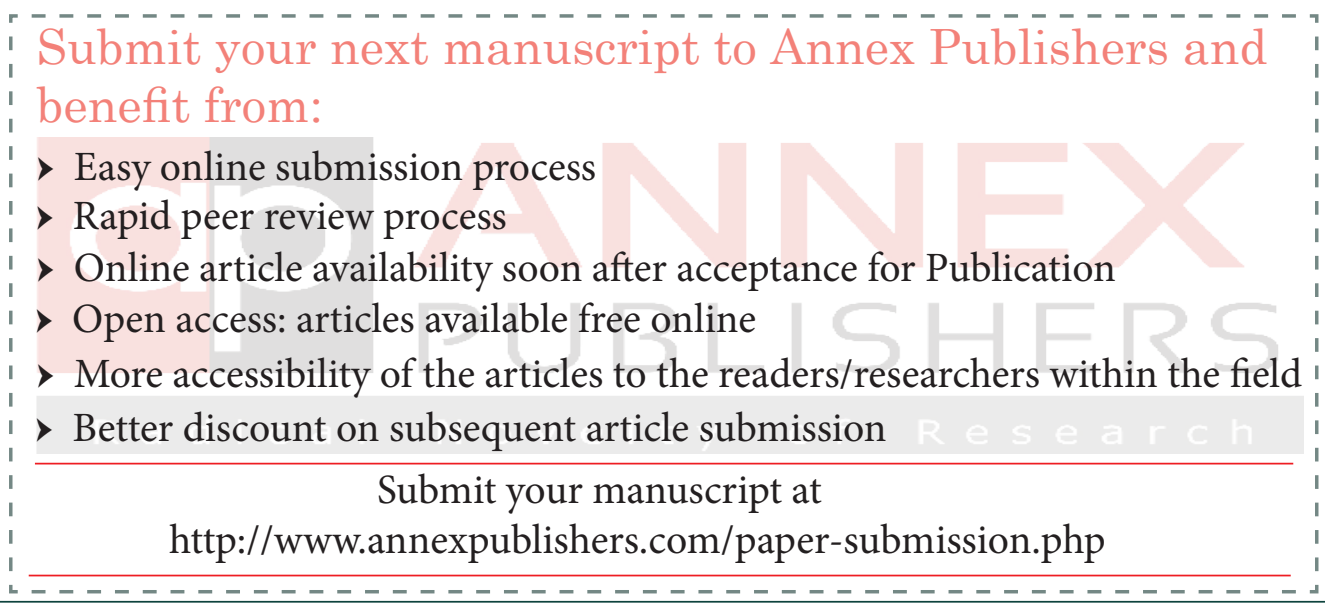

